\title{
Correlation and path analysis studies in Gladiolus (Gladiolus hybrids Hort.)
}

\author{
T. Vetrivel ${ }^{1 *}$, V. Lakshmanan ${ }^{2}$ and M. Jawaharlal ${ }^{3}$ \\ ${ }^{1}$ Imayam Institute of Agriculture and Technology, Thuraiyur, Trichy - 621206 (Tamilnadu), INDIA \\ ${ }^{2}$ Department of Horticulture, HC \& RI, TNAU, Peiyakulam 625604(Tamilnadu), INDIA \\ ${ }^{3}$ Horticultural College and Research Institute, TNAU, Coimbatore - 641003(Tamilnadu), INDIA \\ *Corresponding author. E-mail: thnivesa@gmail.com \\ Received: August 8, 2017; Revised received: September 13, 2017; Accepted: January 27, 2018
}

\begin{abstract}
Correlation and path analysis were carried out in 12 varieties of gladiolus for different yield attributing traits at the Horticultural Research Station, Tamil Nadu Agricultural University, Yercaud. The results indicated that the Rachis length was positive and significantly correlated with mother corm weight $(\mathrm{g})$, plant height at $60^{\text {th }}$ days after planting $(D A P)(\mathrm{cm})$, number of leaves per plant at $60^{\text {th }}(\mathrm{DAP})$, length of spike $(\mathrm{cm})$, weight of daughter corm $(\mathrm{g})$ and vase life (days). But, it is negative and significantly correlated with number of days taken for first floret opening ( $\mathrm{rg}:-0.714$ \& rp: -0.664), number of daughter corms per plant ( $\mathrm{rg}:-0.826$ \& rp: -0.724 ) and marketable spikes per plant (rg: -0.561 \& rp: -0.418 ) at both genotypic and phenotypic levels. For path analysis the residual effect was 0.174 and it was evident that the highest direct effect on length of rachis was observed in case of mother corm size (0.951) and weight of the daughter corm (0.943), followed by number of daughter corms per plant (0.859), number of florets per spike (0.849), length of first floret $(0.832)$, marketable spikes per plant $(0.385)$, number of leaves per plant at $60^{\text {th }}$ DAP (0.384), diameter of first floret (0.374) and length of spike $(0.221)$ under Shevaroys conditions
\end{abstract}

Keywords: Correlation and path analysis, Gladiolus, Shevaroys conditions and varieties

\section{INTRODUCTION}

Gladiolus (Gladiolus hybridus Hort.), a member of family Iridaceae. It is the "Queen of bulbous flowers". It occupies $5^{\text {th }}$ place in international cut flower trade (Butt et al., 2015). Gladiolus has a long noble history. The genus gladiolus comprises about 250 species. The name gladiolus was originally coined by Elder (23-79 AD) from the Latin word 'gladius' meaning a sword, on account of the sword like shape of the foliage. 'Corn flag' is another common name in Europe because, Gladiolus primulinus is found wild as weed in the cornfields. It is commonly called sword lily and about 114 species out of 226 in the genus Gladiolus are native of South Africa. Gladiolus primulinus is also known as waterfall gladiolus (Mishra et al., 2003). It was introduced into cultivation by the end of sixteenth century (Innes, 1985).

In India, its germplasm has been screened but the information on the performance for the higher yield of the cut flower and yield contributing parameters of gladiolus is meager. In spite of varietal development there is needed to evaluate the varieties/ genotypes for better yield, quality and their adaptation under different environment. Because a variety may perform well only in a particular environment and therefore the genetic potentiality of different genotypes and their interaction with environmental condition are to be estab- lished and according to their performance, selection of best growth and flowering traits genotype needs to be done.

Correlation study provides beneficial information regarding the interrelationship of quantitative traits among each other and influence of these traits on yield, thereby aid in selection. The path coefficient analysis deals with the direct and indirect relationship of predicted variable with the responsible variables which help in assessing the relative influence of significant traits on the ultimate yield. Therefore, present investigations were carried out to generate such information for gladiolus.

\section{MATERIALS AND METHODS}

The experiment was carried out at the Horticultural Research Station, Tamil Nadu Agricultural University, Yercaud with twelve varieties of gladiolus (Arka Kesar, Darshan, Kum Kum, Sagar, Sapna, Shobha, Sindur, Tilak, Sanjeeveeru, Dr. Flemming, Gold Dust and Pssittacinus Hybrid) in Randomized block design (RBD) with three replications. The observations were recorded on five randomly selected plants per genotype of each replicate for sixteen characters like weight of mother corm $(\mathrm{g})$, size of mother corm $(\mathrm{cm})$, plant height at $60^{\text {th }}$ DAP $(\mathrm{cm})$, number of leaves per plant at $60^{\text {th }}$ DAP, number of days taken for first floret open (days), length of spike (cm), length of rachis 
(cm), number of florets per spike, length of first floret (cm), diameter of first floret $(\mathrm{cm})$, number of daughter corms per plant, number of cormels per plant, weight of daughter corm $(\mathrm{g})$, diameter of daughter corm $(\mathrm{cm})$, marketable spikes per plant and vase life (days). Correlation coefficient and path analysis were computed as per method as suggested by Al-Jibouri et al. (1958), Miller et al. (1958) and Dewey and Lu (1959).

\section{RESULTS AND DISCUSSION}

The correlation coefficients (genotypic and phenotypic) between different characters in chrysanthemum are presented in Table 1 and 2. In the present investigation for most of the characters genotypic correlation coefficient was found to be higher in the phenotypic correlation co-efficient, indicating a strong inherent association among various characters and were masked by environmental component with regard to phenotypic expression. Similar observations were made by Pattanik et al. (2015) in gladiolus.

Average weight of mother corm showed strong and significant correlation with Size of mother corm (rg:0.425, rp:0.455), plant height at $60^{\text {th }}$ DAP (rg:0.375, rp:0.361), length of spike (rg:0.448, rp:0.432), length of rachis (rg:0.622, rp:0.593), number of florets per spike (rg:0.400, rp:0.376), diameter of first floret (rg:0.549, rp:0.521), weight of daughter corm (rg:0.777, rp:0.620), size of daughter corm (rg:0.751, rp:0.609) and vase life (rg:0.624, rp:0.579) at both genotypic and phenotypic levels. So by planting a bigger corm we can have good spikes and planting materials. Rashmi (2006) and Archana (2006) also observed positive significant correlation between weight of mother corm and other characters like length of spike, number of cormels per plant and number of florets per spike. Similar results were reported by Maurya et al. (2011) in gladiolus.

Diameter of mother corm was correlated significantly and positively with weight of mother corm (rg:0.425, rp:0.455), number of daughter corms per plant (rg:0.593, rp:0.405), number of cormels per plant (rg:0.767, rp:0.643), diameter of daughter corm (rg:0.655, rp:0.466) and marketable spikes per plant (rg:0.67, rp:0.364) at both genotypic and phenotypic levels.

Plant height exhibited positive significant correlation at genotypic level with weight of mother corm (rg:0.375, rp:0.361), number of leaves per plant at $60^{\text {th }}$ DAP (rg:0.763, rp:0.695), length of spike (rg:0.551, rp:0.503), length of rachis (rg:0.664, rp:0.606), number of florets per spike (rg:0.728, rp:0.664), length of first floret (rg:0.539, rp:0.494), diameter of first floret (rg:0.679, rp:0.623), weight of daughter corm (rg:0.480, rp:0.411) and vase life (rg:0.755 and rp:0.689) and it is similar to the findings of Archana (2006) in gladiolus.
Number of leaves per plant at $60^{\text {th }}$ DAP, was positively and significantly correlated with plant height at $60^{\text {th }}$ DAP (rg:0.763, rp:0.695), length of spike (rg:0.610, rp:0.559), length of rachis (rg:0.654, rp:0.584), number of florets per spike (rg:0.525, rp:0.464), length of first floret (rg:0.531, rp:0.478), diameter of first floret (rg:0.606, rp:0.537) and vase life (rg:0.717, rp:0.653) at both genotypic and phenotypic levels. So, more number of leaves means more plant height and length of spike, because of the increased photosynthesis leading to the availability of more photosynthates purposes.

Number of days taken for first floret opening was significantly and positively correlated with number of daughter corms per plant (rg:0.502, rp:0.385) at both genotypic and phenotypic levels. Length of spike had positive significant correlation with characters like weight of mother corm (rg:0.448, rp:0.432), plant height at $60^{\text {th }}$ DAP (rg:0.551, rp:0.503), number of leaves per plant at $60^{\text {th }}$ DAP (rg:0.610, rp:0.559), length of rachis (rg:0.831, rp:0.822), number of florets per spike (rg:0.647, rp:0.638), length of first floret (rg:0.794, rp:0.789), diameter of first floret (rg:0.620, rp:0.613), weight of daughter corm (rg:0.606, rp:0.527) and vase life (rg:0.627, rp:0.625). All these characters are indirectly affected by the weight of mother corm as it had positive significant correlation with length of spike. This is attributed to good supply of stored food materials from the corms having more weight to the developing spike. Similar results have been obtained by Ranchana et al. (2015) in tuberose. In the present study, length of rachis had positive significant correlation with characters such as weight of mother corm (rg:0.622, rp:0.593), plant height at $60^{\text {th }}$ DAP (rg:0.664, rp:0.606), number of leaves per plant at $60^{\text {th }}$ DAP (rg:0.654, rp:0.584), length of spike (rg:0.831, rp:0.822), length of first floret (rg:0.706, rp:0.698), diameter of first floret (rg:0.928, rp:0.919), weight of daughter corm (rg:0.806, rp:0.709) and vase life (rg:0.807, rp:0.784). All these characters are indirectly affected by the weight of mother corm as it had positive significant correlation with length of spike. This is attributed to good supply of stored food materials from the corms having more weight of the developing rachis. Size of floret increased and length of rachis and spike also increased, because the florets occupied more area of spike and rachis. Similar results have been obtained by Kumar and Kumar (2010) in snapdragon.

Number of florets per spike had positive significant correlation with Number of florets per spike was positively and significantly association with weight of mother corm (rg:0.790, rp:0.516), plant height at $60^{\text {th }}$ DAP (rg:0.728, rp:0.664), number of leaves per plant at $60^{\text {th }}$ DAP (rg:0.525, rp:0.464), length of spike (rg:0.647, rp:0.638), length of rachis (rg:0.703, rp:0.695), length of first floret (rg:0.574, rp:0.571), diameter of first floret (rg:0.633, rp:0.625), weight of daughter corm (rg:0.744, rp:0.648) and vase life of the 
T. Vetrivel et al. / J. Appl. \& Nat. Sci. 10 (1): 216 - 221 (2018)
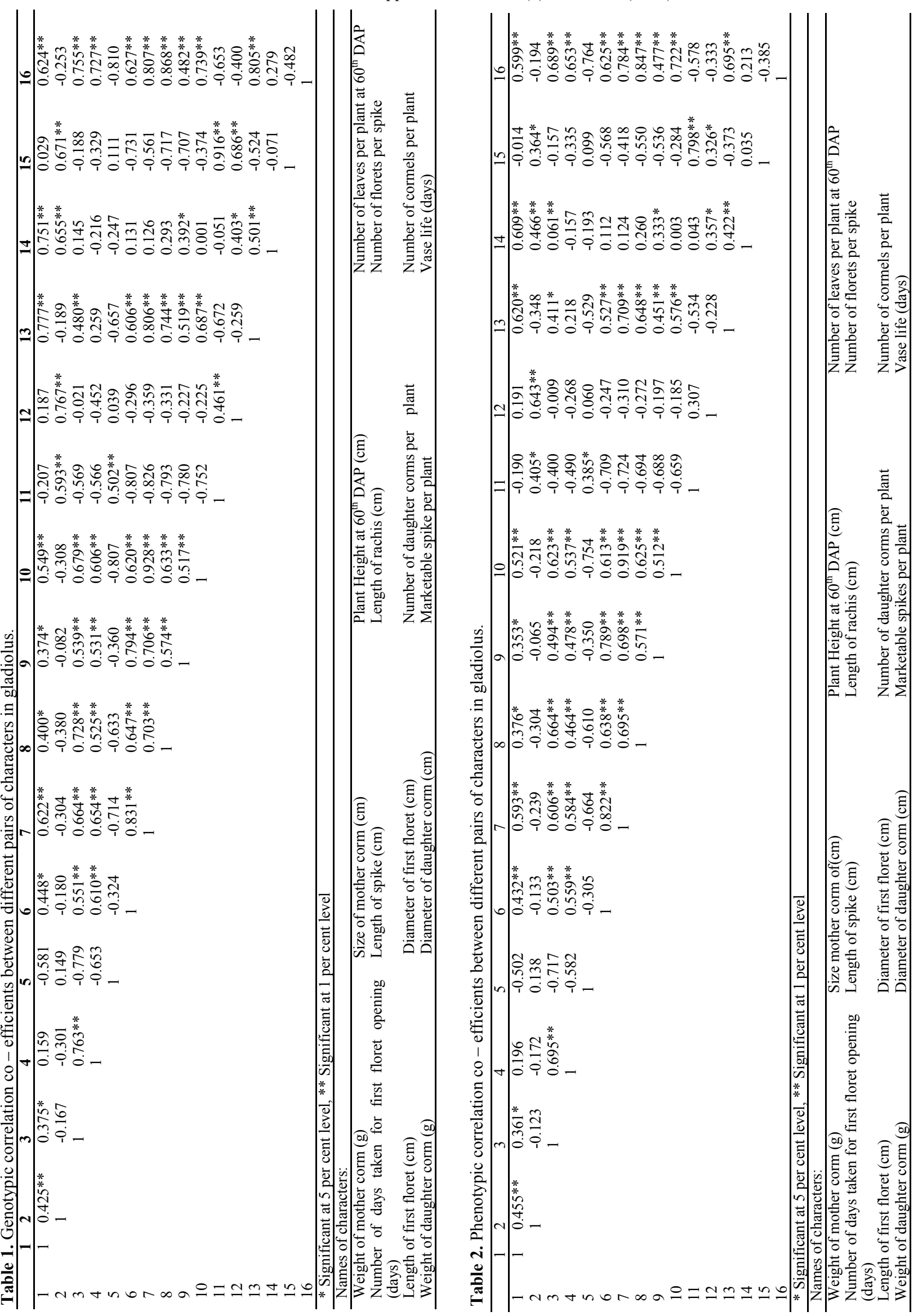


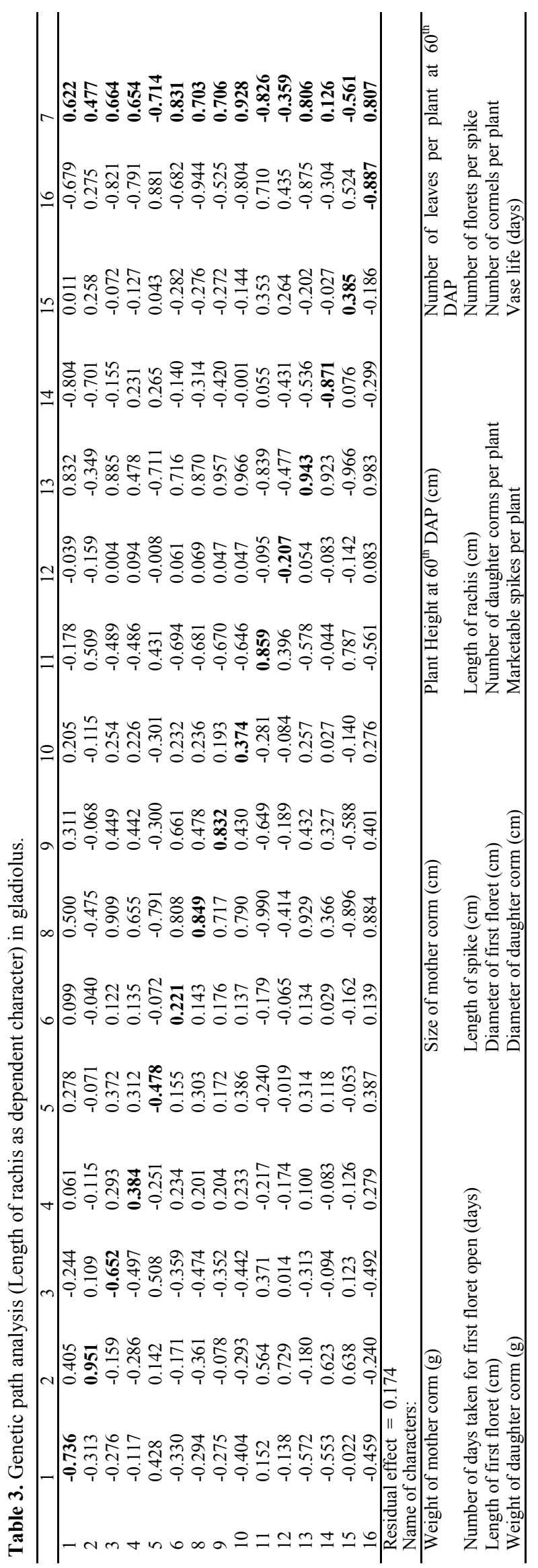

cut flower (rg:0.868, rp:0.847) at both genotypic and phenotypic levels. By increasing the length of spike and rachis to increase the number of florets per spike. Increasing the number of florets per spike, increased the vase life. These similar results are observed by Rashmi (2006).

Length of first floret showed positive association with weight of mother corm ( $\mathrm{rg}: 0.374$, rp:0.353), plant height at $60^{\text {th }}$ DAP (rg:0.539, rp:0.494), number of leaves per plant at $60^{\text {th }}$ DAP (rg:0.531, rp:0.478), length of spike (rg:0.794, rp:0.789), length of rachis (rg:0.706, rp:0.698), number of florets per spike (rg:0.574, rp:0.571), diameter of first floret (rg:0.517, rp:0.512), weight of daughter corm (rg:0.519, rp:0.451), diameter of daughter corm ( $\mathrm{rg}: 0.392$ rp:0.333) and vase life (rg:0.482, rp:0.477) at both genotypic and phenotypic levels of significance. Diameter of first floret was positively correlated with weight of mother corm (rg:0.549, rp:0.0.521), plant height at $60^{\text {th }}$ DAP ( $\mathrm{rg}: 0.679, \mathrm{rp}: 0.623$ ), number of leaves per plant at $60^{\text {th }}$ DAP (rg:0.606, rp:0.537), length of spike (rg:0.620, rp:0.613), length of rachis ( $\mathrm{rg}: 0.928$, rp:0.919), number of florets per spike (rg:0.633, $\mathrm{rp}: 0.625$ ), length of first floret (rg:0.517, rp:0.512), weight of daughter corm (rg:0.687, rp:0.576) and vase life (rg:0.739, rp:0.722) at both genotypic and phenotypic levels of significance.

Good multiplication ratio is very much essential for commercial expansion of any crop. The number of daughter corms per plant showed positive correlation with size of mother corm (rg:0.593, rp:0.405), number of days taken for opening of first floret (rg:0.502, rp:0.385) and marketable spikes per plant (rg:0.916, rp:0.798) at both genotypic and phenotypic levels. Number of cormels per plant was positively and significantly correlated with size of mother corm (rg:0.767, rp:0.643), diameter of daughter corm (rg:0.403, rp:0.357) and marketable spikes per plant (rg:0.686, rp:0.326) at both genotypic and phenotypic levels. It indicated that less production of cormels per plant had produced good quality spike. In contrast, Mishra and Saini (1990) reported no correlation of cormels per plant with plant height in gladiolus. They also recorded week negative association of cormels counts with number of florets per spike and week positive relation with length of spike in gladiolus and similar observations were also recorded by Basavaraddy (2004) and Rashmi (2006) in gladiolus.

Weight of daughter corm was significantly and positively correlated with weight of mother corm ( $\mathrm{rg}: 0.777$, rp:0.620), plant height at $60^{\text {th }}$ DAP (rg:0.480, rp:0.411), length of spike (rg:0.606, rp:0.527), length of rachis ( $\mathrm{rg}: 0.806$, rp:0.709), number of florets per spike (rg:0.744, rp:0.648), length of first floret (rg:0.519, rp:0.459), diameter of first floret ( $\mathrm{rg}: 0.687$, rp:0.576), diameter of daughter corm (rg:0.501, rp:0.422) and vase life (rg:0.805, rp:0.695) at both gen- 
otypic and phenotypic levels. Diameter of daughter corm was significantly and positively correlated with weight of mother corm (rg:0.751, rp:0.609), size of mother corm (rg:0.655, rp:0.466), length of first floret (rg:0.392, rp:0.333), number of cormels per plant (rg:0.403, rp:0.357), weight of daughter corm (rg:0.501, rp:0.422) and vase life (rg:0.805, rp:0.695) at both genotypic and phenotypic levels.

Marketable spikes per plant showed high negative association with number of leaves per plant at $60^{\text {th }} \mathrm{DAP}$ (rg: -0.329 , rp: -0.335 ), length of spike (rg: -0.731 , rp: -0.568), length of rachis (rg: $-0.560 \mathrm{rp:}-0.418$ ), number of florets per spike (rg: $-0.717 \mathrm{rp}$ : -0.550 ), length of first floret (rg: $-0.707 \mathrm{rp}:-0.536$ ), weight of daughter corm (rg: -0.524 , rp: -0.373) and vase life (rg: 0.482 , rp: -0.385 ) at both genotypic and phenotypic levels. Vase life had highly positive and significant correlation with weight of mother corm (rg:0.624, rp:0,599), plant height at $60^{\text {th }}$ DAP (rg:0.755, rp: $0.689)$, number of leaves per plant at $60^{\text {th }}$ DAP (rg:0.727, rp:0.653), length of spike (rg:0.627, rp:0.625), length of rachis (rg:0.807, rp:0.784), number of florets per spike (rg:0.868, rp:0.847), length of first floret (rg:0.482, rp:0.477), diameter of first floret (rg:0.739, rp:0.722) and weight of daughter corm (rg:0.805, rp:0.695) at both genotypic and phenotypic levels.

In the present study like length of rachis has taken dependent variable, whereas remaining fifteen characters were considered as independent variables contributing towards length of rachis. The data is presented in Table 3. Spike characters are very important with respect to cut flower production of quality spikes. Among the characters length of rachis is considered to be important and contributing greater to it's commercial quality.

Path analysis is useful in unraveling these two effects and was first suggested by Wright (1921) and subsequently elaborated by $\mathrm{Li}$ (1956). This is simply a standardized partial regression analysis, which is based on cause and relationship, which serves to analyses by sub dividing correlation in a causal scheme. Dewey and $\mathrm{Lu}$ (1959) were perhaps the first to adopt this technique in the determination of yield components in crested wheat grass and they demonstrated the utility of this method in plant selection. Since then, it is being extensively utilized by plant scientists so as to get a clean picture of association of various plant characters. In this study, the residual effect of path analysis was 0.174 . From this study, it was evident that the highest direct effect on length of rachis was observed in case of mother corm size (0.951) and weight of the daughter corm (0.943), followed by number of daughter corms per plant (0.859), number of florets per spike (0.849), length of first floret (0.832), marketable spikes per plant $(0.385)$, number of leaves per plant at $60^{\text {th }}$ DAP (0.384), diameter of first floret (0.374) and length of spike (0.221).

The direct effects shown by the rest of the characters under study were negative irrespective of their moderate to high positive correlations with length of rachis in most of the cases. Vase life had high magnitude of negative direct effect on -0.887 , followed by diameter of daughter corm (-0.871), weight of mother corm ($0.736)$, plant height at $60^{\text {th }}$ DAP $(-0.652)$, number of days taken for first floret opening $(-0.478)$ and number of cormels per plant $(-0.207)$. Hegde (1994) reported that marketable spikes had positive direct effect on length of rachis, whereas, size of mother corm, length of spike, weight of daughter corm had positive direct effect on length of rachis. Number of florets per spike had highly significant genotypic correlation with length of rachis, which was due to it's direct and indirect effects through number of cormels per plant, weight of mother corm. Similar results were obtained by Sandhu et al. (1990) in gladiolus. Who observed high positive correlation between length of rachis and number of florets per spike in gladiolus and similar observations were made by Basavaraddy (2004) in gladiolus. However, the findings of Mishra and Saini (1990) and Hegde (1994) indicated a weak negative correlation of length of rachis with number of florets per spike in gladiolus.

\section{Conclusion}

The findings of the present study may be drawn; most of the characters have higher genotypic correlation coefficient than phenotypic correlation coefficient. For good yield (Number of marketable spikes per plant) of gladiolus varieties is also very much influenced by the factors like size of mother corm and its weight and also environmental conditions. Hence the cut flower quality parameters like length of spike, length of rachis, number of florets per spike, size of floret etc. are likely to be influenced by the size of mother corm.

\section{REFERENCES}

Al-Jibouri, H. A., P.A. Miller and H.F. Robinson. (1958). Genotypic and environmental variances and covariances in and upland cotton cross of interspecific origin. Agron. J., 50: 633-636.

Archana B. B. (2006). Evaluation of gladiolus hybrids (Gladiolus hybridus Hort.) for yield and quality cut flower production. M.Sc. (Agri.) Thesis, University of Agricultural Sciences, Dharwad, Karnataka, India.

Basavaraddy, M. (2004). Evaluation of elite hybrids of gladiolus for cut flower production under transition tract of Karnataka. M.Sc. (Agri) Thesis, University of Agricultural Sciences, Dharward, Karnataka, India.

Butt S.J., Varis S. Nasir I.A., Sheraz S., Shahid A., and Ali Q., 2015, Micro Propagation in Advanced Vegetable Production: A Review. Adv. Life Sci., 2(2): 48-57

Dewey, D.R. and K.H. Lu. (1959). A correlation and path coefficient analysis of components of crested wheat grass seed 
production. Agron. J., 51(9): 515-518

Hegde, M. V., (1994). Studies of variability, correlation, path analysis and performance of gladiolus hybrids. M.Sc., (Agri) Thesis. University of Agricutural scinces, Dharwad Karnataka, India.

Innes, C., (1985). The world of Iridaceae, a comprehensive record. Holly Gate International Limited, England.

Kumar, R. and Kumar, S. (2010). Correlation studies in snapdragon (Antirrhinum majus L.). J. Orna. Hortic., 13(2):133-137.

Li, C.C. (1956). Biometrics. The concept of path co-efficient and impact on population genetics. 12, 190-210.

Maurya, P.K., Binayak, R.K., Chakraborty, R.M. and Mishra, D.S. (2011). Genetic variability and correlation studies in gladiolus under Tarai condition. Ann. Hortic., 4 (2): 140-146.

Miller, P. A., Willioms, C.V., Robinson, H.F. and Comstock, R.E. (1958). Estimates of genotypic and environment variance and co-variance in upland cotton and their implication in selection. Agron J 50 (3): 126-131.

Mishra, R.L. and Saini, H.C., (1990). Correlation and path coefficient studies in gladiolus. Indian J. Hort., 47(1): 127-132.

Mishra, R.L., Singh, B. and Palai, S.K., (2003). Gladiolus In: Commercial Flowers (vol.2). Edt. Bose, T.K., Yadav, L.P., Pal, P., Parthasarathy, V.A. and Das, P., Nayaudoyog Pubilishers, Kolkata. India. pp1-112.

Pattanik, S., Paul, A. and Lenka, P.C. (2015). Genotypic and phenotypic variability studies in gladiolus. J. Crop Weed, 11(1): 113-119.

Ranchana, P., Kannan, M. and Jawaharlal, M. (2015). Assessment of genetic and correlation studies in single types of tuberose (Polianthes tuberosa). J.N.A.Ag.Sc., $33: 2$.

Rashmi, L. (2006). Evaluation of promising hybrids gladiolus. M.Sc. (Agri.) Thesis, University of Agricultural Sciences, Dharwad, Karnataka, India.

Sandhu, G.P.S., Sharma, S.C. and Arora, J.S. (1990). Association among morphological traits in gladiolus. J. Punjab Hort., 30 (1-4): 191-194.

Wright, S. (1921). Correlation and causation. J. Agri. Res., 20: 557-585 